\title{
Pré-Tratamento Físico: Um Procedimento Importante para o Aumento na Resolução Espectral em Estudos de Microestrutura de Polímeros por RMN ${ }^{13} \mathrm{C}$ em Solução
}

\author{
Oscar J. 0. Pedroza, Maria I. B. Tavares \\ Instituto de Macromoléculas Professora Eloisa Mano, UFRJ
}

\begin{abstract}
Resumo: Em um material polimérico as variações nas propriedades físicas podem ser avaliadas pelo conhecimento da sua microestrutura. Os estudos de microestrutura em materiais poliméricos são geralmente realizados por ressonância magnética nuclear (RMN) em solução empregando o núcleo de carbono-13. Neste tipo de estudo a resolução espectral é muito importante e esta depende do preparo da amostra. Foi observado que um pré-tratamento físico permite obter uma melhor resolução espectral e, por conseqüência, informações mais detalhadas sobre os encadeamentos nas cadeias poliméricas podem ser obtidos. Isto facilita a determinação das estereoseqüências.
\end{abstract}

Palavras chave: Microestrutura, RMN, pré-tratamento físico.

\section{Pre- Physical Treatment: An Important Procedure to Improve Spectral Resolution in Polymers Microstructure Studies Using ${ }^{13} \mathrm{C}$ Solution NMR}

Abstract: Changes in physical properties of polymeric materials can be evaluated from their microstructures, which can be investigated using solution carbon-13 nuclear magnetic resonance (NMR). In this type of study spectral resolution is very important, which obviously depend on the sample and solvent. A pre physical treatment allows for an improvement in the spectral resolution. Consequently, more information on chain linking can be obtained, thus facilitating the determination of the stereosequences.

Keywords: Microstructure, NMR, pre- physical treatment.

\section{Introdução}

As variações nas propriedades físicas de um material polimérico podem ser explicadas pelo conhecimento detalhado de suas estrutura e microestrutura ${ }^{[1,2]}$.

No estudo da microestrutura a resolução espectral, em relação ao espectro de RMN de carbono-13 ${ }^{[3-7]}$, é muito importante, ao assinalamento dos tipos de carbono presentes. Assim quanto melhor definida forem as linhas de ressonância mais detalhado poderá ser o assinalamento em termos de pêntades ${ }^{[5-8]}$. O principal objetivo deste trabalho é avaliar a microestrutura de materiais poliméricos atáticos em diferentes formas físicas para determinar o maior número possível de sequiências de encadeamentos das unidades monoméricas.

\section{Experimental}

Foram preparados filmes com o poliestireno (PS) por diferentes pré-tratamentos físicos: filme vazado (solução de clorofórmio), filme prensado e filme prensado e resfriado rapidamente. Após o pré-tratamento físico de cada material, estes foram redissolvidos e avaliados por $\mathrm{RMN}{ }^{13} \mathrm{C}$ em solução e a resolução espectral foi comparada com a do poliestireno comercial.

$\mathrm{Na}$ avaliação do núcleo de ${ }^{13} \mathrm{C}$, foram utilizadas as condições padrão no equipamento de RMN, VARIAN MERCURY 300, freqüência $75,4 \mathrm{MHz}$, que estão descritas a seguir:

Intervalo de reciclo entre os pulsos $-1 \mathrm{~s}$,

Pulso de $90^{\circ}$,

Tempo de aquisição: $1,59 \mathrm{~s}$

Número de pontos: 60032

\section{Resultados e Discussão}

Durante o desenvolvimento do método analítico para a determinação dos dez tipos de pêntades do poliestireno, foi observado que a resposta do material polimérico com relação à resolução espectral foi melhorada quando se fez o prétratamento físico neste material ${ }^{[1]}$. O pré-tratamento físico consistiu na formação de filmes vazados, filmes fundidos, prensados ou prensados e resfriados. Quando estes filmes eram redissolvidos para avaliação por $\mathrm{RMN}{ }^{13} \mathrm{C}$ em solução geravam espectros com uma melhor resposta face à resolução espectral deste material ${ }^{[1]}$. Observou-se o aumento da resposta na resolução espectral em análise por espectroscopia de $\mathrm{RMN}{ }^{13} \mathrm{C}$ (em solução) para o poliestireno comercial.

Autor para correspondência: Maria I. B. Tavares, Instituto de Macromoléculas Professora Eloisa Mano, UFRJ, Cidade Universitária, Centro de Tecnologia, Ilha do Fundão, Caixa Postal 68525, CEP:21945-970, Rio de Janeiro, RJ.E-mail: mibt@ima.ufrj.br 
As Figura $1 \mathrm{e}$ Tabela 1 mostram respectivamente os espectros de $\mathrm{RMN}$ de ${ }^{13} \mathrm{C}$ em solução de $\mathrm{CDCl}_{3}$ das amostras de PS sem e com os diferentes pré-tratamentos físicos e os valores de deslocamentos químicos obtidos dos espectros dos quatro tipos de amostras.

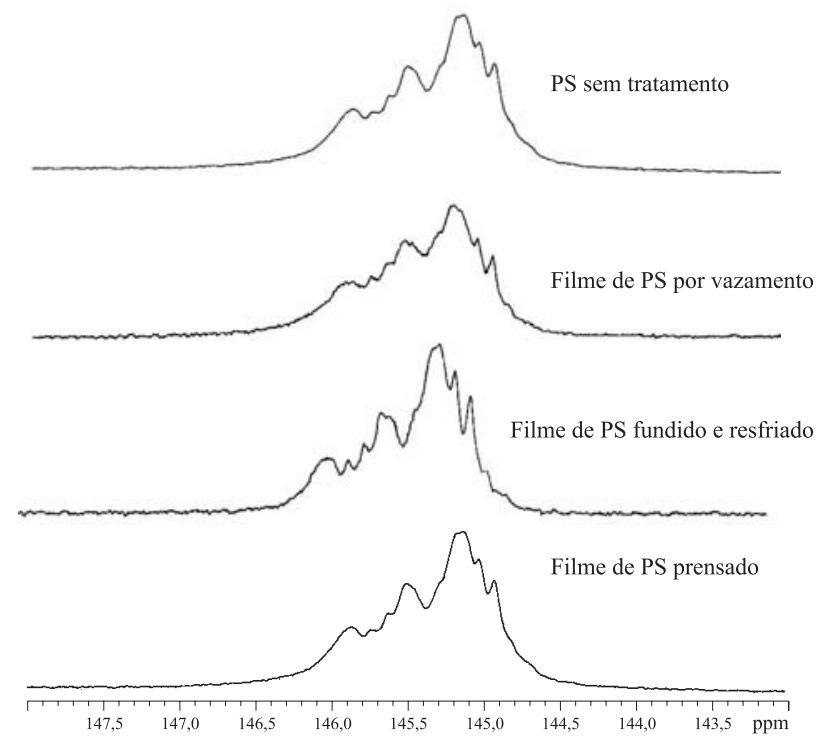

Figura 1. Espectro de RMN ${ }^{13} \mathrm{C}$, em solução, das amostras de filmes de PS

Tabela 1. Assinalamentos e encadeamentos dos filmes de PS sem e com tratamento físico, determinados por $\mathrm{RMN}{ }^{13} \mathrm{C}$ em solução

\begin{tabular}{lcccc}
\hline $\begin{array}{c}\text { Tipo de } \\
\text { microestrutura }\end{array}$ & PS & PS FV & PS P & PS FR \\
& \multicolumn{4}{c}{$\begin{array}{c}\text { Assinalamento } \\
(\mathrm{ppm})\end{array}$} \\
\hline $\mathrm{rrrr}$ & 144,94 & 144,95 & 144,94 & 144,95 \\
$\mathrm{mrrr}$ & 145,04 & 145,05 & 145,04 & 145,04 \\
$\mathrm{mrrm}$ & 145,14 & 145,15 & 145,20 & 145,16 \\
$\mathrm{rmrr}$ & 145,18 & 145,19 & 145,20 & 145,19 \\
$\mathrm{rmrm}$ & 145,18 & 145,50 & 145,47 & 145,45 \\
$\mathrm{mmrr}$ & 145,51 & 145,55 & 145,52 & 145,54 \\
$\mathrm{mmrm}$ & 145,65 & 145,66 & 145,65 & 145,65 \\
$\mathrm{rmmr}$ & 145,75 & 145,76 & 145,75 & 145,76 \\
$\mathrm{mmmr}$ & 145,87 & 145,89 & 145,87 & 145,88 \\
$\mathrm{mmmm}$ & 145,87 & 145,89 & 145,91 & 145,91 \\
\hline
\end{tabular}

Onde: PS FV - filme de PS obtido por vazamento PS P - filme de PS obtido por prensagem PS FR - filme de PS obtido por fusão e resfriamento rápido

\section{Conclusões}

O pré-tratamento físico propiciou uma melhoria na resolução espectral quando comparado com o espectro do polímero sem tratamento. Usando as condições padrão no aparelho de RMN foi possível obter a resolução completa em nível de pêntades para o carbono aromático 1 do poliestireno obtido como filme prensado e resfriado rapidamente A melhoria na resolução espectral permitiu o assinalamento completo das 10 pêntades para carbonos substituídos ou metínicos. $\mathrm{O}$ assinalamento completo em nível de pêntades permitirá ter um melhor controle de qualidade, com base na espectroscopia de RMN ${ }^{13} \mathrm{C}$ em solução para o PS.

\section{Agradecimentos}

Capes e CNPq, PRONEX.

\section{Referências Bibliográficas}

1. Pedroza, O. J. O. - Tese de Mestrado, Instituto de Macromoléculas Eloisa Mano, Universidade Federal de Rio de Janeiro (2003).

2. Tonelli, A. E. - NMR spectroscopy and polymer microstructure. The conformational conection, vch publishers Inc., New York, (1989).

3. Bovey, F. A. \& Miaru, P. A. - "NMR of Polymers", Academic Press, New York, (1996)

4. Phan, Q.; Petiaud, R.; Waton, H. and Darricades, M. F. L. - "Proton and Carbon NMR Spectra of Polymers", Penton Press, London, (1991)

5. Edbon, J. R.; Huckerby, T. N. and Senogles, E. - Polymer, $24,339,(1983)$

6. Silva, E. P. and Tavares, M. I. B. - Polymer Bulletin, 41, 307, (1998)

7. Souza, C. M. G.; Pacheco, C. R. and Tavares, M. I. B. - J. Appl. Polym. Sci., 73, 221, (1999)

8. Fraga, L. A.; Coutinho, F. M. B.; Costa, M. A. S. \& Tavares, M. I. B. - Polímeros Ciência e Tecnologia, (2003)

Enviado: $17 / 06 / 04$

Aprovado: 30/08/04 